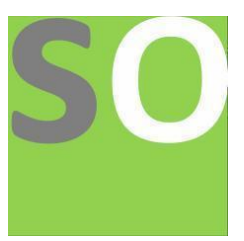

Article title: 24 sectors DTC control with fuzzy hysteresis comparators for DFIM fed by 3 level inverter Authors: Mustefa Jibril[1]

Affiliations: Dire Dawa University, Dire Dawa, Ethiopia[1]

Orcid ids: 0000-0002-3165-2410[1]

Contact e-mail: mustefazinet1981@gmail.com

License information: This work has been published open access under Creative Commons Attribution License http://creativecommons.org/licenses/by/4.0/, which permits unrestricted use, distribution, and reproduction in any medium, provided the original work is properly cited. Conditions, terms of use and publishing policy can be found at https://www.scienceopen.com/.

Preprint statement: This article is a preprint and has not been peer-reviewed, under consideration and submitted to ScienceOpen Preprints for open peer review.

DOI: 10.14293/S2199-1006.1.SOR-.PPDGIWU.v1

Preprint first posted online: 19 December 2021 


\title{
24 sectors DTC control with fuzzy hysteresis comparators for DFIM fed by three-level inverter
}

\author{
Mustefa JIBRIL \\ School of Electrical \& Computer Engineering, Dire Dawa Institute of \\ Technology, Dire Dawa, Ethiopia \\ mustefa.jibril@ddu.edu.et
}

\begin{abstract}
This article presents 24 sectors direct torque control (DTC) with fuzzy hysteresis comparators for the doubly-fed induction motor (DFIM) using a three-level neutral point clamped (NPC) inverter. The designed DTC technique of the DFIM combines the advantages of the DTC strategy and fuzzy logic controller. The reaching conditions, stability, and robustness of the DFIM with the designed DTC technique are guaranteed. The designed DTC technique is insensitive to uncertainties, including parameter variations and external disturbances in the whole control process. Finally, the designed DTC technique with fuzzy hysteresis comparators is used to regulate the electromagnetic torque and the flux of the DFIM fed by the three-level NPC inverter and confirms the validity of the designed DTC technique. Results of simulations containing tests of robustness and tracking tests are presented.
\end{abstract}

Key-Words: -Doubly fed induction motor, Direct torque Control, 24 sectors, Fuzzy Logic Controller .

\section{Introduction}

The doubly-fed induction machine can give an awfully appealing arrangement particularly for variable-speed applications such as electric vehicles wind turbine systems [1]-[5]. Due to its low cost, simplicity of construction, robustness, good performance, reliability, and easy maintenance, and it can operate in a great range of speed variation around the synchronous speed, As well it can be controlled easily those parameters (power flow, power factor). These all advantages have encouraged a lot of researchers to develop and ameliorate it constantly [6].

As consequence, DFIM control has known a great consideration and many control techniques have been proposed and validated experimentally, which the first control techniques have been developed was the field-oriented control (FOC)[7], this command is based on a decoupling between the torque and the flux, It renders the behavior of DFIM similar to that of the DC machine. This decoupling provides a wide speed control range and very fast torque response. But, its major drawbacks are sensitivity to parametric variations of the machine and the complexity of implementation [8]. After this control, the researchers developed a new strategy of control this control is the direct torque control (DTC) was introduced by Takahashi [9][10] and Depenbrock [11]. In this control, we controlled directly the torque and stator flux by using the selection of the optimum voltage vector. The switching logic command facilitates the generation of the stator voltage space vector, with a convenient choice of the switching pattern of the inverter, and he must know: the sector, the amplitude of the stator flux, the torque. The DTC technique is characterized by good stability, a fast torque response, precision, high robustness, good decoupling between the torque and flux and low complexity than other controls. However, the DTC has major disadvantages namely: (a) high ripples in the flux and electromagnetic torque caused by hysteresis controllers, these ripples generate undesirable acoustic noise and mechanical vibrations [12]. (b) degradation of the quality of the output power because the variable switching frequency causes switching losses and current distortions. (c) problems at low speed when we negligence of stator resistance. 
In recent years, several improvements have been made to enhance the DTC control in order to reduce torque ripple [13, 14] and achieved constant switching frequency such as direct mean torque control (DMTC) [15], direct torque control with space vector modulation (DTC-SVM) [16], DTC control based on super twisting algorithm (DTCSTA) [17], neural direct torque control (NDTC) [18], fuzzy direct torque control (FDTC) [19], intelligent seven-level DTC strategy [20], and DTC strategy based on third-order sliding mode controller [21].

In this paper, we present a new direct torque control scheme of the DFIM functioning in motor mode, two methods are suggested for control of DFIM: the first is the traditional 24 sectors DTC strategy using a lookup table, and the second strategy is the 24 sectors DTC technique based on the fuzzy hysteresis comparators. The objective of the proposed DTC technique is to minimize the ripples in the current, stator flux, and electromagnetic torque and to guarantee the best performances regarding the robustness vis-a-vis the variations of its parameters $(R s, R r, L s, L r \ldots)$ and the load torque.

Thus, the novelty and main contributions of this research study are as follows:

1) This work proposed an intelligent 24 sectors DTC technique of the DFIM drives;

2) A new intelligent technique to flux and torque ripples minimization for 24 sectors DTC technique is proposed;

3) Fuzzy logic controllers to minimize error tracking torque and flux references of DFIM drives;

4) Using the designed strategy and three-level inverter to minimize the total harmonic distortion of current/voltage and flux/torque ripple of the DFIM drives.

The theoretical and simulation study of the designed 24 sectors DTC method based on fuzzy logic technique is validated by the simulation results obtained. The rest of the work is organized as follows. Section 2 points out necessary equations related to the mathematical modeling of the DFIM drives. The three-level inverter is presented in Section 3. 24 sectors DTC control theory is presented in section 4. Section 5 explains the designed intelligent 24 sectors DTC strategy for DFIM drives. Matlab software-based simulation studies are presented in section 6 . The conclusion is given in Section 7.

\section{Modeling of the DFIM and his alimentation}

In the literature, we find that the DFIM model in the reference $\alpha \beta$ is summarized in three types of equations: electrical, magnetic, and electromagnetic [22].

\subsection{Electrical equations}

In the frame $\alpha \beta$, the stator and rotor voltages are expressed by the following equations:

$$
\left\{\begin{array}{c}
v_{s \alpha}=R_{s} i_{s \alpha}+\frac{d \Psi_{s \alpha}}{d t} \\
v_{s \beta}=R_{s} i_{s \beta}+\frac{d \Psi_{s \beta}}{d t} \\
v_{r \alpha}=R_{r} i_{r \alpha}+\frac{d}{d t} \Psi_{r \alpha}+\omega \Psi_{r \beta} \\
v_{r \beta}=R_{r} i_{r \beta}+\frac{d}{d t} \Psi_{r \beta}-\omega \Psi_{r \alpha}
\end{array}\right.
$$

With :

$\omega=\omega_{s}-\omega_{r}$

\subsection{Flux equations}

The stator and rotor fluxes are given by:

$\left\{\begin{array}{l}\Psi_{s \alpha}=L_{s} i_{s \alpha}+M i_{r \alpha} \\ \Psi_{s \beta}=L_{s} i_{s \beta}+M i_{r \beta} \\ \Psi_{r \alpha}=L_{r} i_{r \alpha}+M i_{s \alpha} \\ \Psi_{r \beta}=L_{r} i_{r \beta}+M i_{s \beta}\end{array}\right.$

\subsection{Electromagnetic torque}

The equation of the electromagnetic torque as a function of the stator flux and stator current is given by the expression below:

$T_{e}=\frac{3}{2} p\left(\Psi_{s \beta} i_{s \alpha}-\Psi_{s \alpha} i_{s \beta}\right)$

\section{Three-level NPC inverter}

The use of the NPC multilevel inverter exist in various industrial applications among other multilevel inverter topology it's introduced by Baker and Nabae in 1981, they're using the diode to limit the power voltage stress to obtaining a good output voltage waveform and minimize harmonic distortion, and must increase in the number of levels of the inverter [23].

The three-level inverter has great advantages compared to two-level inverter, and it's demonstrated by the researches [24]. The topology 
that has been used in this work is a three-level neutral point clamped inverter. Fig. 1 shows the block diagram of the three-level NPC inverter. The voltage over the phase winding of the DFIM can take one of the three levels $(0,1,2)$ count on the switching states of the inverters. The representation of the space voltage vectors of a three-level NPC inverter for all switching states is offering by Fig. 2.

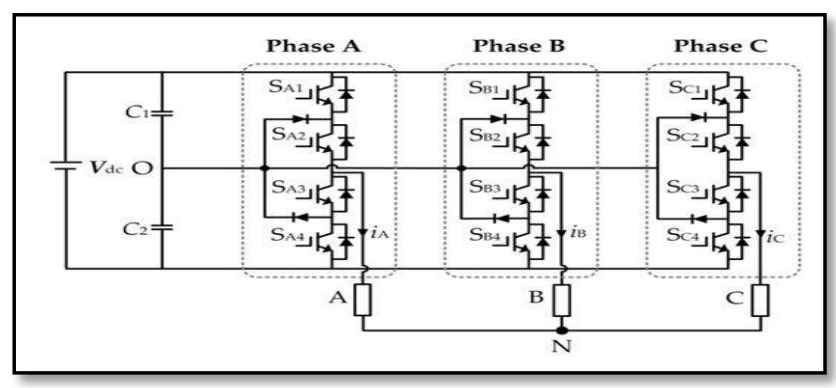

Fig.1 Schema of three-level inverter with NPC structure.

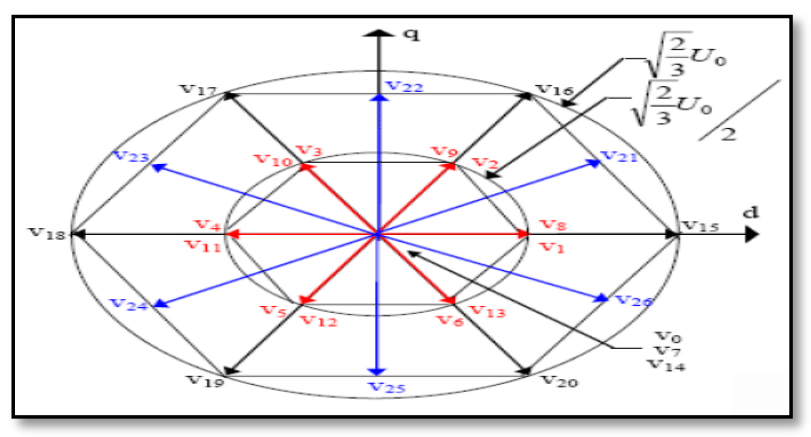

Fig. 2 Voltage vectors delivered by the three-level inverter.

\section{4 sectors DTC control}

The DTC technique is based directly on the determination of the control sequence applied to the switches of the static power converter in order to require the desired levels of torque and flux [25].

The main objective of a DTC is to maintain the electromagnetic torque and the module of the stator flux inside the hysteresis bands by choosing the output voltage of the inverter [26]. At the time, when the module of the torque or of the stator flux reaches the upper or lower limit of the hysteresis, a suitable voltage vector is applied to get the quantity involved inside its hysteresis band. To choose the voltage vector, it is necessary to know the rules for the development of the module of the torque and the stator flux [27].
The stator flux vector is estimated from the measurementsof the voltages and currents of the DFIM. The expression of thestator flux is written:

$\left\{\begin{array}{l}\Psi_{s \alpha}=\int_{0}^{t}\left(v_{s \alpha}-R_{s} \cdot I_{s \alpha}\right) d t \\ \Psi_{s \beta}=\int_{0}^{t}\left(v_{s \beta}-R_{s} \cdot I_{s \beta}\right) d t\end{array}\right.$

The modulus of stator flux is written:

$\Psi_{s}=\sqrt{\Psi_{s \alpha}^{2}+\Psi_{s \beta}^{2}}$

The sector $\mathrm{Si}$ in which one is situated the vector $\Psi_{s}$ was determined from the components $\Psi_{s \alpha}$ and $\Psi_{s \beta}$. The angle $\theta$ s between the referential linked to the stator and the vector $\Psi_{S}$ is equal to:

$\theta_{s}=\operatorname{arctg}\left(\frac{\Psi_{s \beta}}{\Psi_{s \alpha}}\right)$

The error $\boldsymbol{\varepsilon}_{\emptyset_{s}}$ between the estimated flux $\Psi_{S}^{*}$ and the reference flux $\Psi_{s \text { ref }}$, is introduced into a twolevel hysteresis regulator. The latter will generate the binary variable $\left(H_{\Psi}=0,1\right)$ at the output, representing the desired evolution for the flux like shown Fig 3a. The same thing in the error of the torque $\varepsilon_{T_{e}}$ is calculated by comparing itsreference value $T_{e}$ ref and its estimated value $T_{e}^{*}$, then he introduced in the three-level hysteresis regulator, generating at its output the variable with three levels $\left(H_{T_{e}}=-1,0,1\right)$ representing the direction of temporal evolution desired for the torque Fig $3 \mathrm{~b}$.

The state choice of each VSI is made in a switching table elaborated according to the state of the variables $H_{\Psi}$ and $H_{T_{e}}$, as well as sector giving the information about the position of flux vector [28].

The proposed switching table of 24 sectors DTC control scheme of DFIM is presented in Table 1.

The general structure of the DFIM with threelevel DTC 24 sectors is illustrated by the following Fig. 4.

Table 1. Three-level DTC switching table with 24 sectors

\begin{tabular}{|c|c|c|c|c|c|c|}
\hline \multirow{3}{*}{$\mathbf{N}$} & \multicolumn{7}{|c|}{$\mathbf{H}_{\boldsymbol{\Psi}}$} \\
\cline { 2 - 7 } & \multicolumn{7}{|c|}{1} & \multicolumn{3}{|c|}{0} \\
\cline { 2 - 7 } & \multicolumn{7}{|c|}{$\mathbf{H}_{\mathbf{T e}}$} \\
\cline { 2 - 7 } & 1 & 0 & -1 & 1 & 0 & -1 \\
\hline 1 & 16 & 8 & 20 & 17 & 11 & 19 \\
\hline 2 & 16 & 8 & 20 & 17 & 11 & 19 \\
\hline 3 & 22 & 9 & 26 & 23 & 12 & 25 \\
\hline 4 & 22 & 9 & 26 & 23 & 12 & 25 \\
\hline
\end{tabular}




\begin{tabular}{|c|c|c|c|c|c|c|}
\hline 5 & 17 & 9 & 15 & 18 & 12 & 20 \\
\hline 6 & 17 & 9 & 15 & 18 & 12 & 20 \\
\hline 7 & 23 & 10 & 21 & 24 & 13 & 26 \\
\hline 8 & 23 & 10 & 21 & 24 & 13 & 26 \\
\hline 9 & 18 & 10 & 16 & 19 & 13 & 15 \\
\hline 10 & 18 & 10 & 16 & 19 & 13 & 15 \\
\hline 11 & 24 & 11 & 22 & 25 & 8 & 21 \\
\hline 12 & 24 & 11 & 22 & 25 & 8 & 21 \\
\hline 13 & 19 & 11 & 17 & 20 & 8 & 16 \\
\hline 14 & 19 & 11 & 17 & 20 & 8 & 16 \\
\hline 15 & 25 & 12 & 23 & 26 & 9 & 22 \\
\hline 16 & 25 & 12 & 23 & 26 & 9 & 22 \\
\hline 17 & 20 & 12 & 18 & 15 & 9 & 17 \\
\hline 18 & 20 & 12 & 18 & 15 & 9 & 17 \\
\hline 19 & 26 & 13 & 24 & 21 & 10 & 23 \\
\hline 20 & 26 & 13 & 24 & 21 & 10 & 23 \\
\hline 21 & 15 & 13 & 19 & 16 & 10 & 18 \\
\hline 22 & 15 & 13 & 19 & 16 & 10 & 18 \\
\hline 23 & 21 & 8 & 25 & 22 & 11 & 24 \\
\hline 24 & 21 & 8 & 25 & 22 & 11 & 24 \\
\hline
\end{tabular}
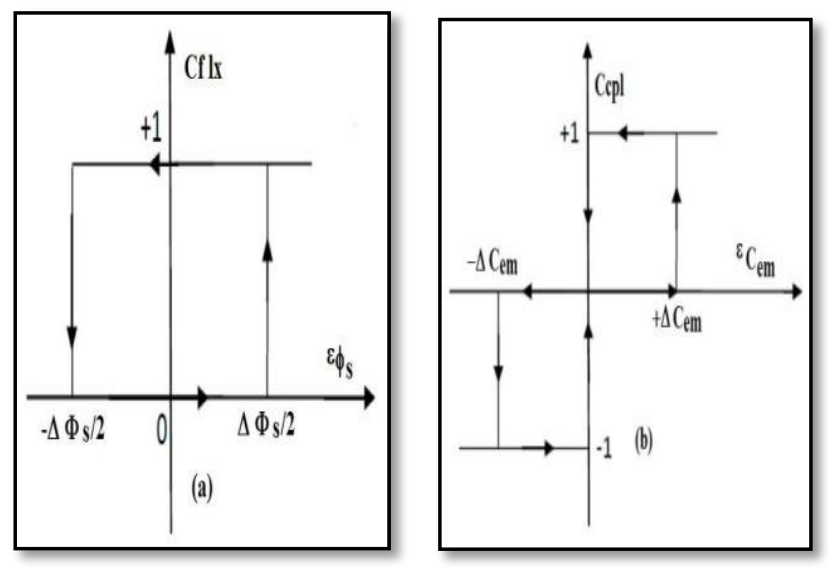

Fig. 3. Hysteresis controllers: (a) Hysteresis comparators of flux, (b)Hysteresis comparator of torque.

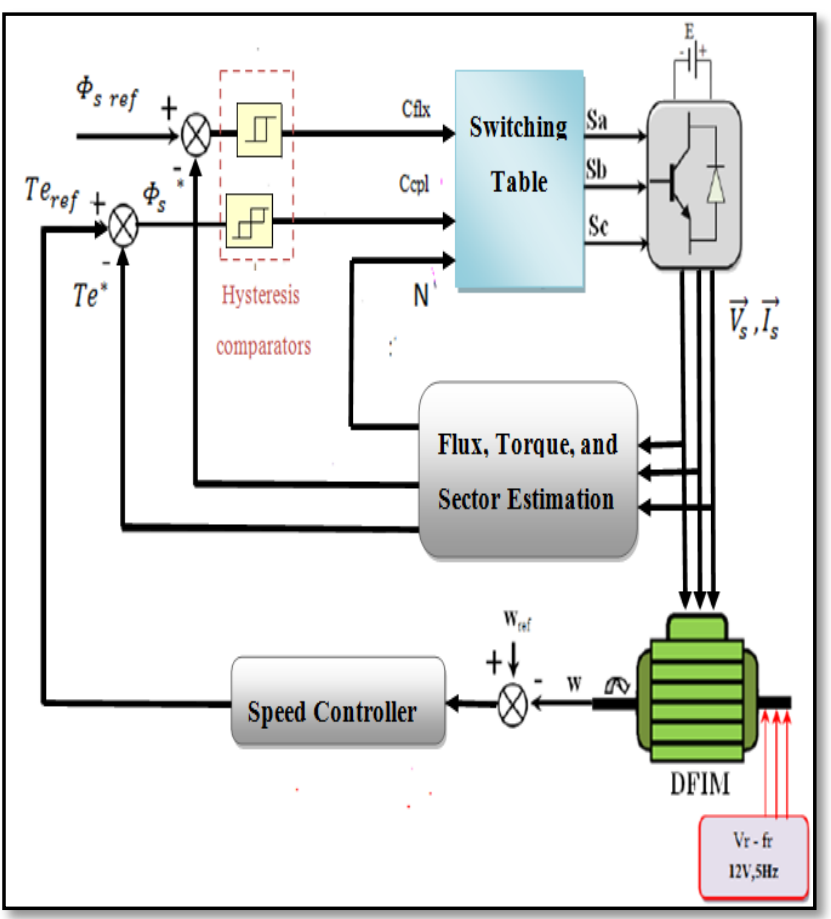

Fig. 4. general structure of the DFIM with threelevel DTC 24 sectors

\section{Proposed DTC control}

In this work, a new intelligent 24 sectors DTC strategy was proposed to control the DFIM fed by a three-level inverter and minimize the torque, stator current, and flux ripples. The proposed intelligent 24 sectors DTC technique is based on the artificial intelligence technique (fuzzy logic). The principle of artificial intelligence techniques direct torque control is similar to the traditional 24 sectors DTC strategy. However, 24 sectors DTC control scheme based on fuzzy logic controllers, to ameliorate the performances of the system and to minimize ripples in the electromagnetic torque and flux, we replace the two controllers of hysteresis of the flux and the torque by a two proposed fuzzy logic controllers

In this system, the flux error and the torque error are considered as inputs to each fuzzy logic controller.

$$
\left\{\begin{array}{c}
\varepsilon_{\boldsymbol{\Psi}_{s}}=\Psi_{\text {sref }}-\Psi_{s}^{*}=\Delta_{\boldsymbol{\Psi}_{s}} \\
\boldsymbol{\varepsilon}_{\boldsymbol{T}_{\boldsymbol{e}}}=T_{\text {eref }}-T_{e}^{*}=\Delta_{\boldsymbol{T}_{\boldsymbol{e}}}
\end{array}\right.
$$


These error functions are the differences between a magnitude calculated by the command and the estimated magnitude.

\subsection{Hysteresis controller of torque and flux based on fuzzy logic}

The fuzzy logic, or more generally the treatment of uncertainties, is one of the classes of artificial intelligence [29], it is introduced to ameliorate the performances and effectiveness of the proposed 24 sectors DTC technique of the DFIM fed by a threelevel NPC inverter. However, the fuzzy logic technique has the capability to control nonlinear uncertain systems even in the case where no mathematical model is available for the control system [30]. On the other hand, fuzzy logic is a simple method, easy to use and robust technique compared to the classical PI controller and other techniques [31].

The fuzzy controller is composed of three blocks: fuzzification, rule bases, and defuzzification like as shown in Fig. 5.

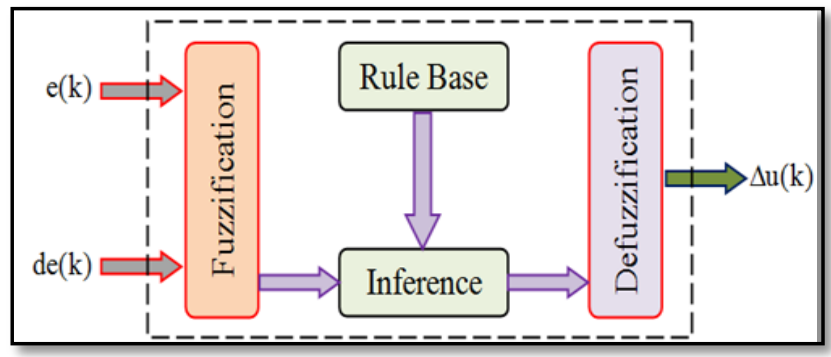

Fig. 5. Structure of fuzzy logic controller.

In this article, the fuzzy logic technique is used to replace hysteresis comparators of torque and flux and improve the performances of the 24 sectors DTC strategy of DFIM. Torque hysteresis comparator and flux hysteresis comparator are compensated because they cause ripples in both torque and flux levels in 24 sectors DTC control.

Fig. 6 shows the block diagram of the flux fuzzy hysteresis comparator and torque fuzzy hysteresis comparator. From this figure, this proposed intelligent hysteresis comparator is a more simple structure, easy to implement, and more robust compared to the traditional hysteresis comparator.

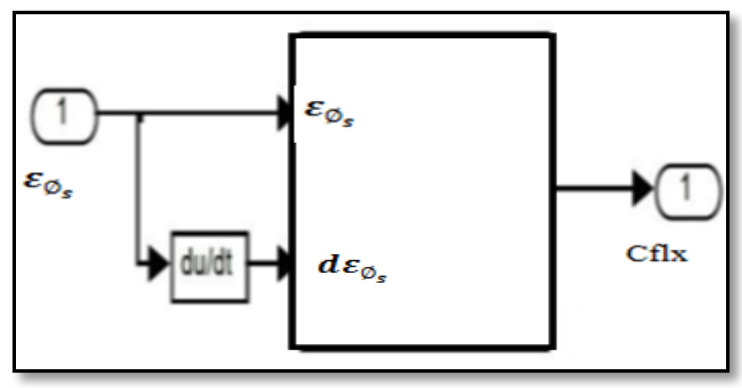

(a)

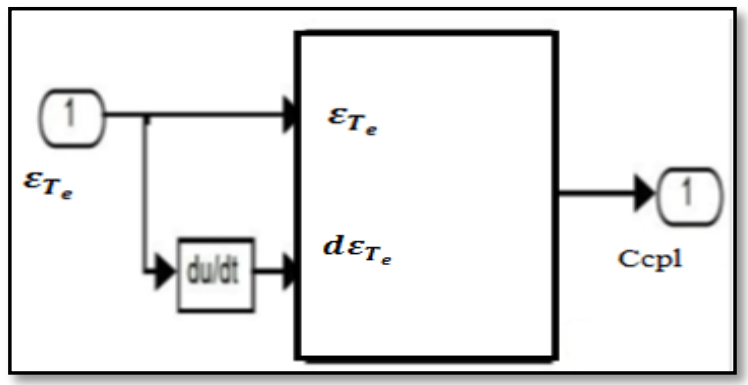

(b)

Fig. 6. Fuzzy hysteresis comparators: a)Fuzzy hysteresis comparator of the flux, b) Fuzzy hysteresis comparator of torque.

The membership function definition for the input variables 'Error in flux hysteresis comparator and Error in torque hysteresis comparator' is shown in Fig. 7a, 'Change in Error of flux hysteresis comparators and torque hysteresis comparator' is shown in Fig. 7b, 'Control' is shown in Fig. 7c [32].

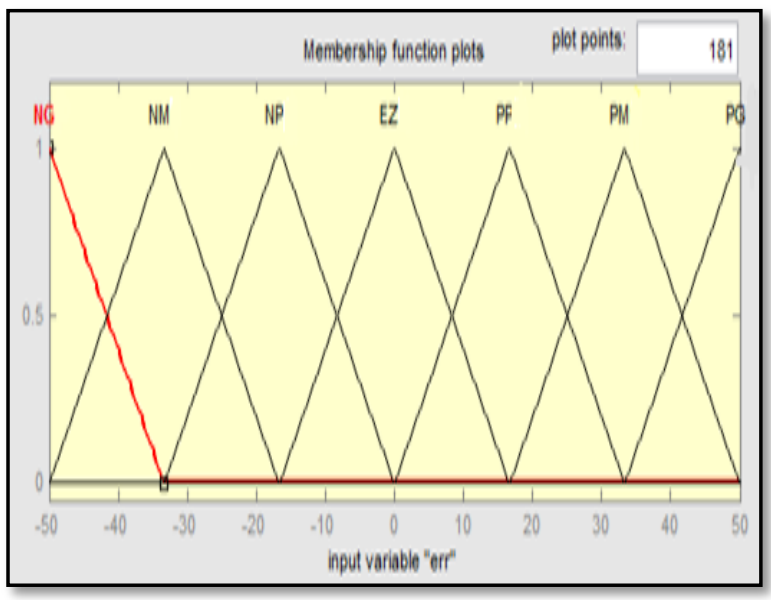

(a)

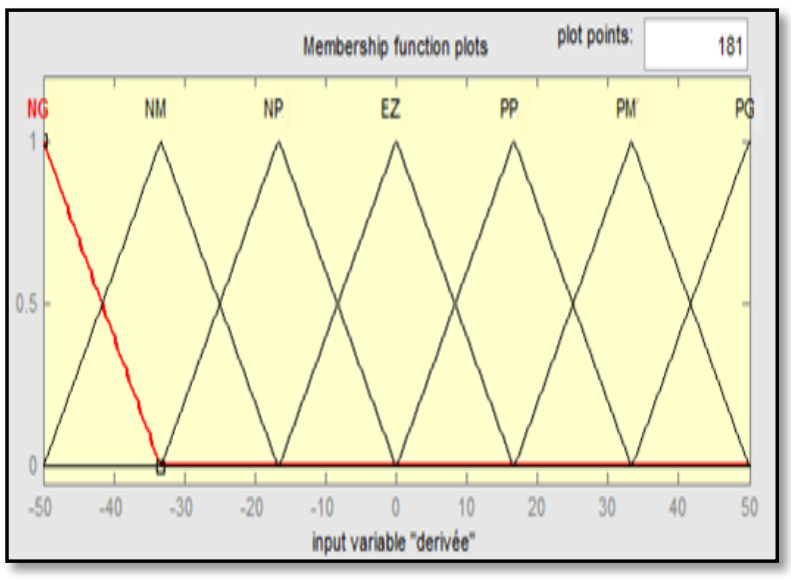

(b) 


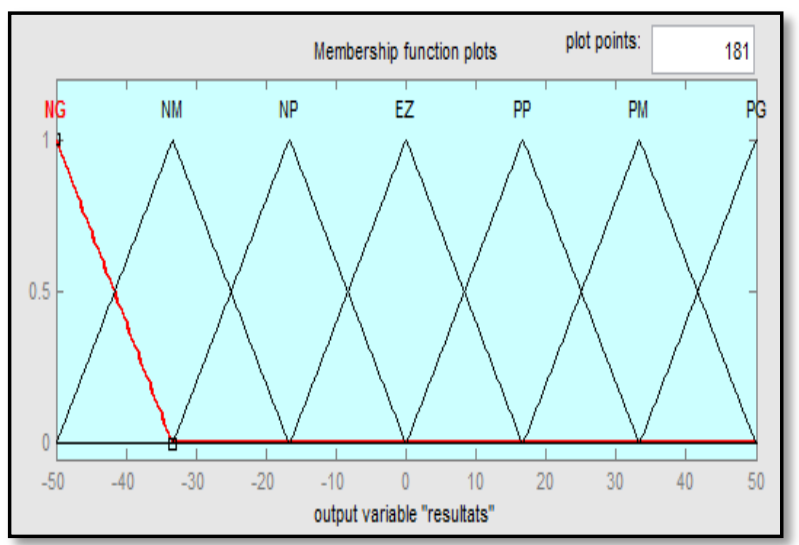

(c)

Fig. 7. Membership function for error, change in error and hysteresis fuzzy controller.

There are 7 fuzzy subsets for each input variable, which gives $7 * 7=49$ possible rules. The rules base is shown in Table 2. Fig. 8 shows the corresponding control surface of the designed fuzzy logic controller.

Table 2. Rules base

\begin{tabular}{|l|l|l|l|l|l|l|l|}
\hline $\begin{array}{l}\text { de } \\
\varepsilon\end{array}$ & NG & NM & NP & ZE & PP & PM & PG \\
\hline NG & NG & NG & NG & NG & NM & NP & $Z E$ \\
\hline NM & NG & NG & NG & NM & NP & ZE & $P P$ \\
\hline NP & NG & NG & NM & NP & ZE & PP & $P M$ \\
\hline ZE & NG & NM & NP & ZE & PP & PM & $P G$ \\
\hline PP & NM & NP & ZE & PP & PM & PG & $P G$ \\
\hline PM & NP & ZE & PP & PM & PG & PG & $P G$ \\
\hline PG & $Z E$ & $P P$ & $P M$ & $P G$ & $P G$ & $P G$ & $P G$ \\
\hline
\end{tabular}

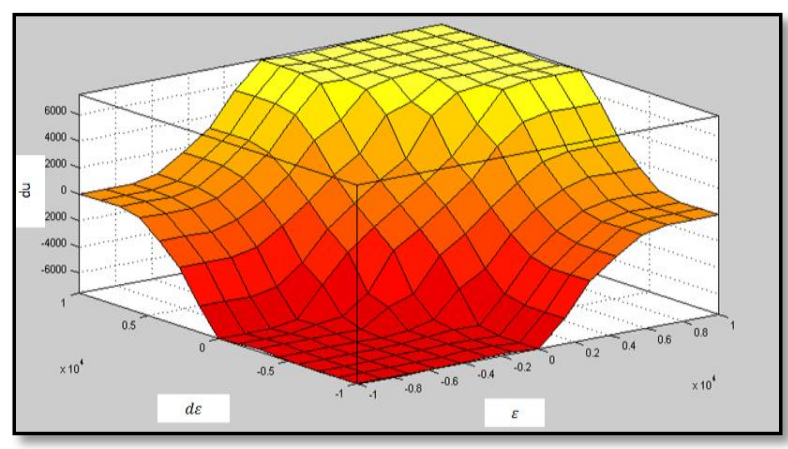

Fig. 8. FLC control surface

The general structure of the intelligent 24 sectors DTC control of the DFIM fed by a three-level inverter is represented by Fig. 9. From this figure, the proposed intelligent 24 sectors DTC technique of the DFIM fed by a three-level NPC inverter is a more simple algorithm, easy to implement, and robust control compared to traditional DTC strategy, field-oriented control, and 24 sectors DTC strategy. The proposed 24 sectors DTC method is almost the same as the classical 24 sectors DTC method, and we have maintained the same algorithm. The difference is in the use of fuzzy logic in torque and flux hysteresis comparators.

In this proposed DTC strategy, fuzzy logic is used to improve the characteristics and effectiveness of the 24 sectors DTC control of the DFIM. Fuzzy logic was used in order to compensate for traditional hysteresis comparators. Using fuzzy logic will improve the value of total harmonic distortion (THD) of stator current and reduce torque and flux ripples.

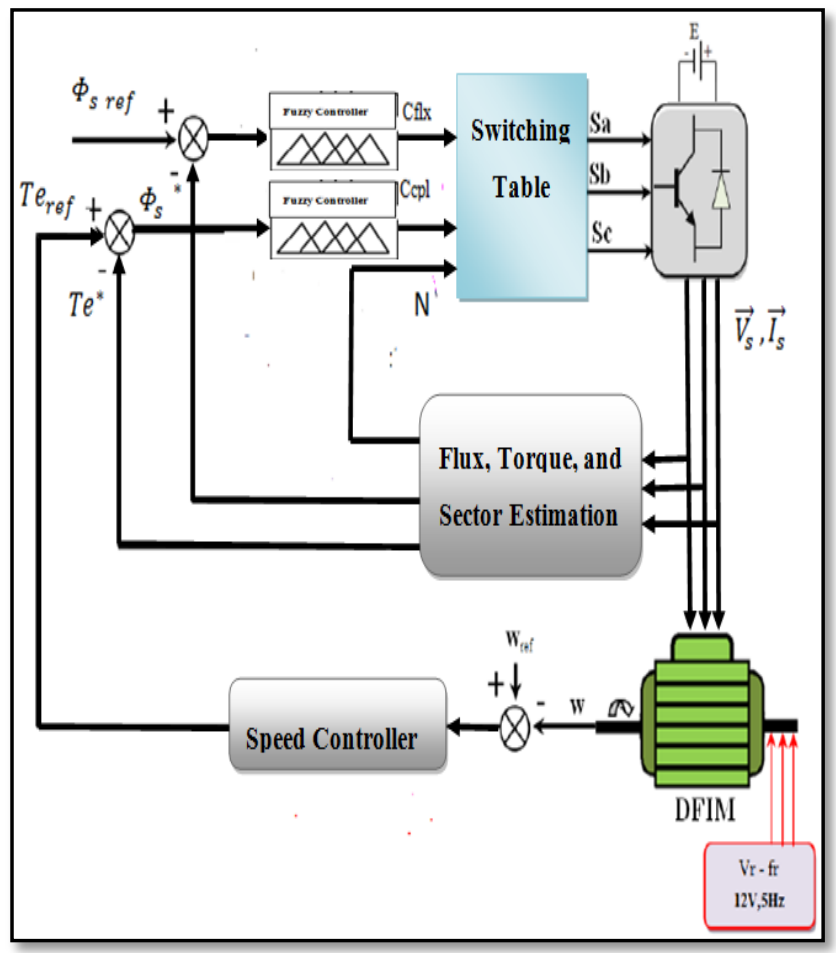

Fig. 9. General structure of the intelligent 24 sectors DTC control of the DFIM system. .

\section{Simulation Results}

In this section, two 24 sectors DTC techniques are designed, simulated, and compared in order to know which of the two 24 sectors DTC strategies is better in improving the characteristics of the DFIM fed by three-level NPC inverter. The designed 24 sectors DTC strategies are 24 sectors DTC strategy with a lookup table and 24 sectors DTC strategy with intelligent hysteresis comparators. The DFIM used in this work is the same as the DFIM used 
in [22]. These 24 sectors DTC strategies were compared in terms of response time, torque ripples, traceability, stator flux, stator current ripples, THD ratio, and durability. Therefore, three tests were proposed in order to find out which the 24 sectors DTC strategy is better.

\subsection{First test}

In this test, the torque reference is changed from 5 N.m to -5 N.m during the $0.5 \mathrm{~s}$ and $1.5 \mathrm{~s}$ time periods.

This test represents the reference tracking test. Obtained results are represented in Figs 10 to 15. Through these figures, we find that torque, speed and flux follow the references very well (see Figs 10 to 12). But the preference of the two designed 24 sectors DTC strategies in terms of response time compared to the classical 24 sectors DTC strategy .

The electric current of the both 24 sectors DTC controls is shown in Fig. 13. Through this figure, we find that the value and shape of the current are related to the torque reference, as there is a direct relationship between them.

Fig. 14 shows the sector of the both 24 sector DTC techniques. The sector value of the both 24 sectors DTC strategies is 24 and this is true of the proposed method for direct torque control.

From Fig. 15, we note that the proposed 24 sectors fuzzy DTC strategy give a minimum THD value compared to the classical 24 sector DTC technique. On the other hand, the proposed 24 sectors DTC strategy minimizes the ripples in torque, stator flux, and stator current compared to the classical 24 sector DTC strategy.

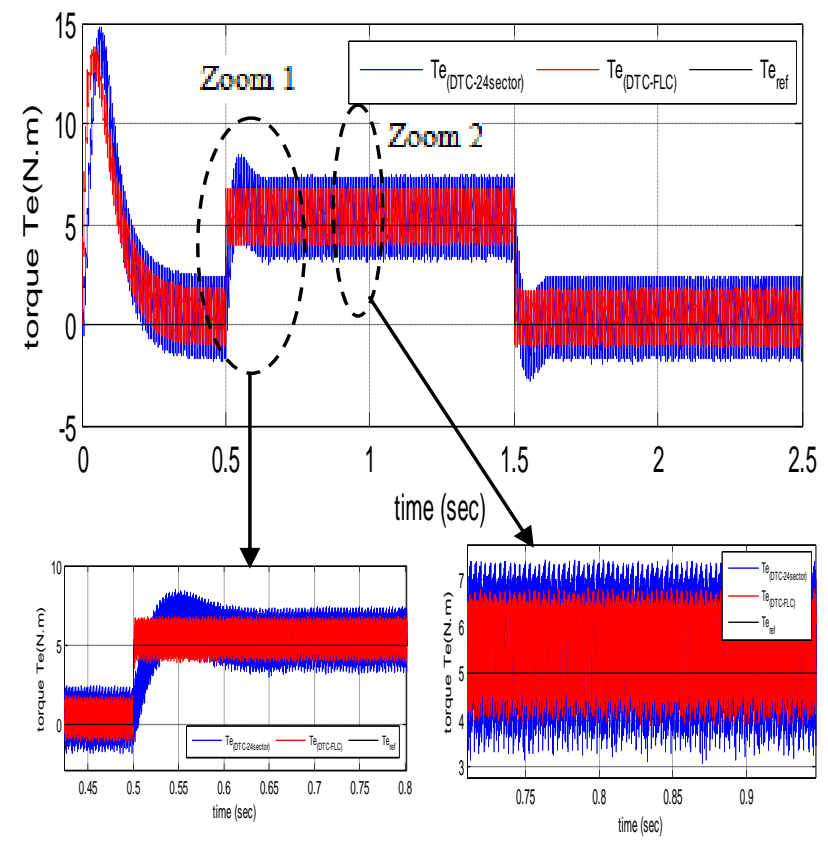

Fig. 10 Torque.
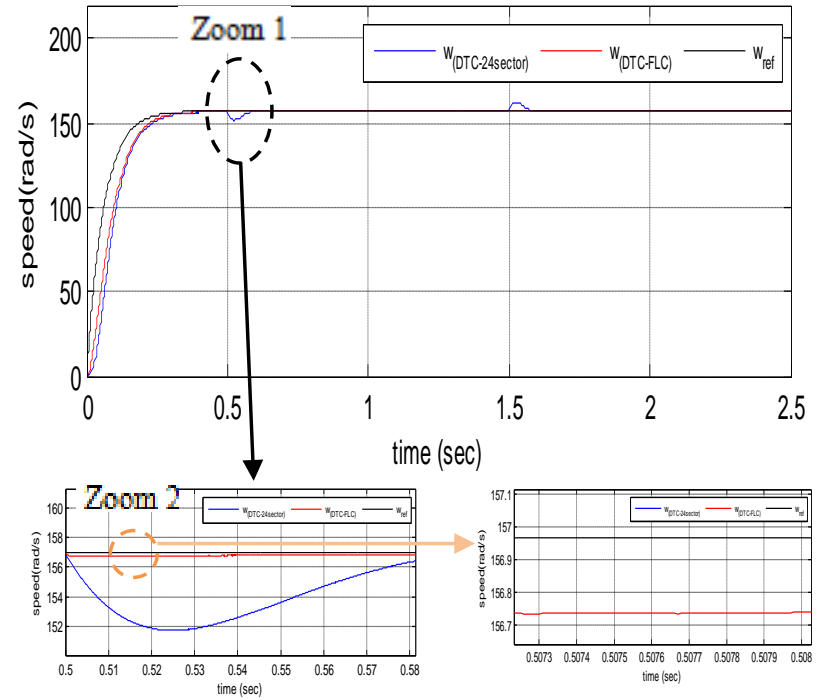

Fig. 11 Speed.

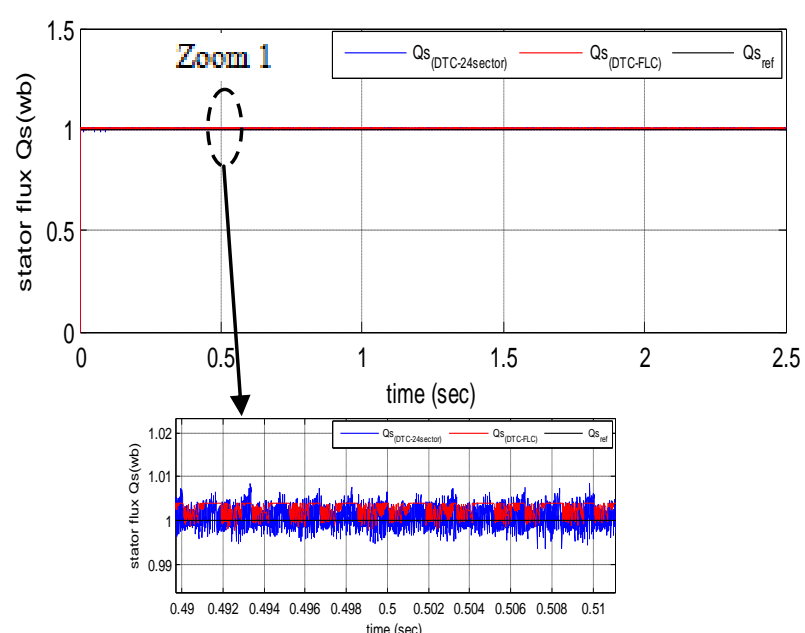

Fig. 12 Flux.

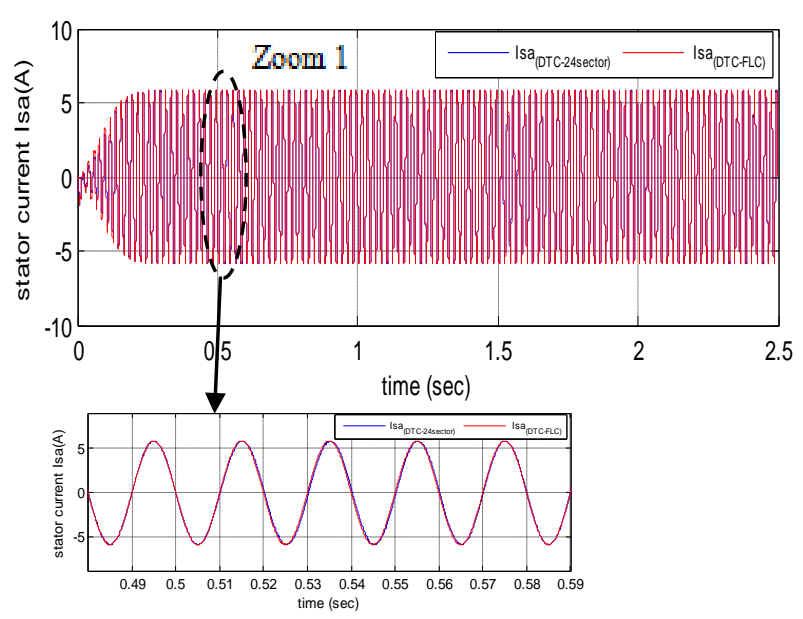

Fig. 13 Stator current. 


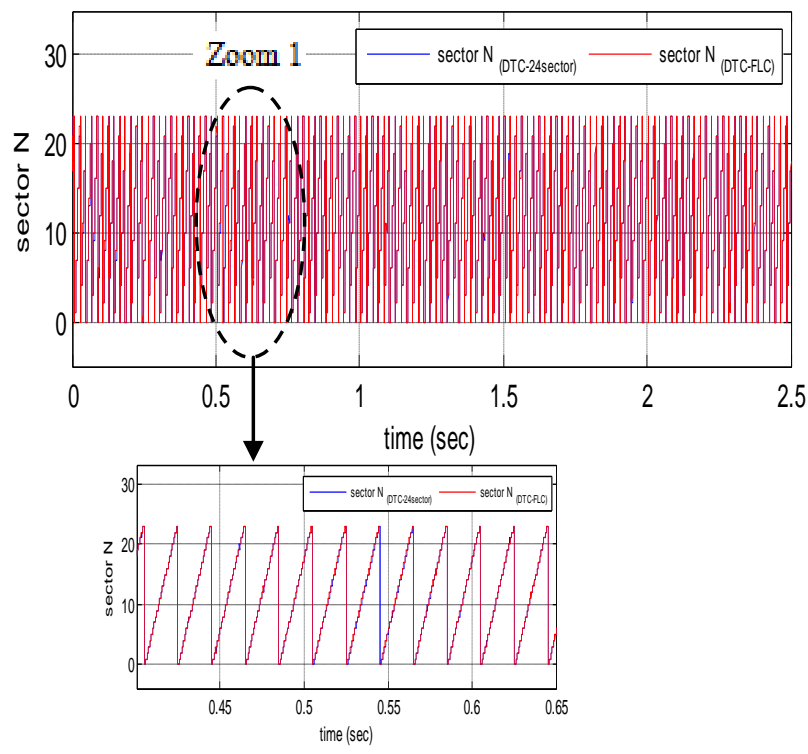

Fig. 14 Sector.

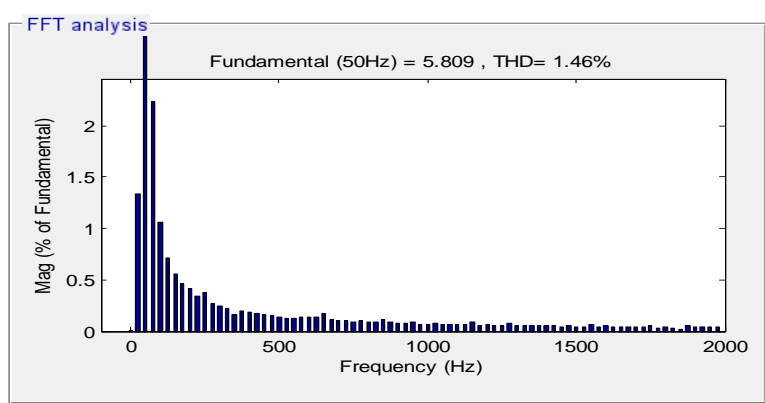

(a)

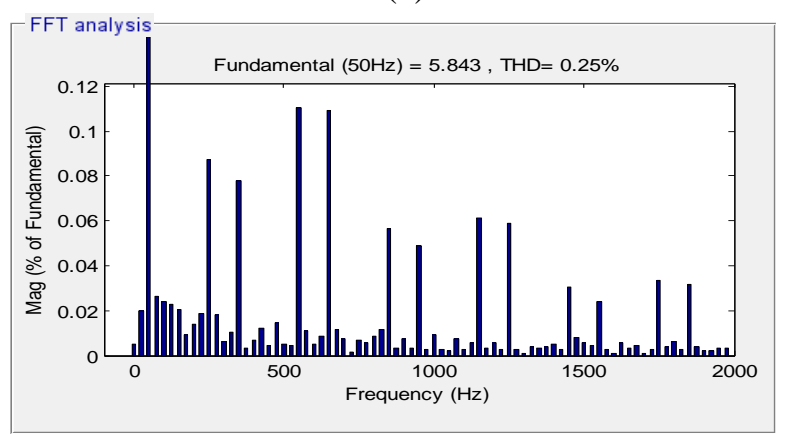

(b)

Fig. 15 THD values: (a) 24 sectors DTC strategy, (b) 24 sectors fuzzy DTC strategy.

In Table 3 the results obtained in this test are summarized. Through this table, we find that the proposed 24 sectors fuzzy DTC method gave better results than the classical 24 sectors DTC method.

Table 3. Comparison between the proposed DTC strategies

\begin{tabular}{|l|c|c|}
\cline { 2 - 3 } \multicolumn{1}{c|}{} & $\begin{array}{c}\text { 24 sectors } \\
\text { DTC }\end{array}$ & $\begin{array}{c}\text { 24 sectors } \\
\text { fuzzy DTC }\end{array}$ \\
\hline Rise Time of & $1.5472 \mathrm{e}+004$ & $1.4755 \mathrm{e}+004$ \\
\hline
\end{tabular}

\begin{tabular}{|l|c|c|}
\hline speed & 3.3379 & 0.1575 \\
\hline $\begin{array}{l}\text { Overshoot } \\
\text { of speed }\end{array}$ & 162.2612 & 157.2550 \\
\hline $\begin{array}{l}\text { Peakof } \\
\text { speed }\end{array}$ & 152486 & 150329 \\
\hline $\begin{array}{l}\text { Peak Timeof } \\
\text { speed }\end{array}$ & 1.46 & 0.25 \\
\hline $\begin{array}{l}\text { THD (\%) of } \\
\text { Isa(A) }\end{array}$ & & \\
\hline
\end{tabular}

\subsection{Second test}

In this test, the speed is changed from $157 \rightarrow-80 \rightarrow 60$ $\mathrm{rad} / \mathrm{s}$ and $\mathrm{Cr}=5 \mathrm{~N} . \mathrm{M}$ between $\mathrm{t}=[0.5 ; 1.5]$.

The main objective of this test is to check the effect of speed change of DFIM on torque, stator flux, and THD value of electric current. Obtained results are represented in Figs 16 to 21. Through these figures, speed, torque, and stator flux follow the references well for all the designed 24 sectors DTC controls (see Figs 16 and 18). Through this test, we note that changing the speed affects the torque and does not affect the flux. As for the electric current, its value remains related to the system and the reference value of the torque (see Fig. 19). The electric current has a sinusoidal shape for the two 24 sectors DTC methods.

Fig. 20 shows the sector of the both 24 sectors DTC strategy of the DFIM fed by a three-level NPC inverter. On the other hand, the proposed 24 sectors fuzzy DTC strategy reduced the torque ripples, current ripples and flux ripples compared to classical 24 sectors DTC control.

The proposed 24 sectors DTC strategy reduced the THD value of the stator current compared to the traditional 24 sectors DTC strategy.

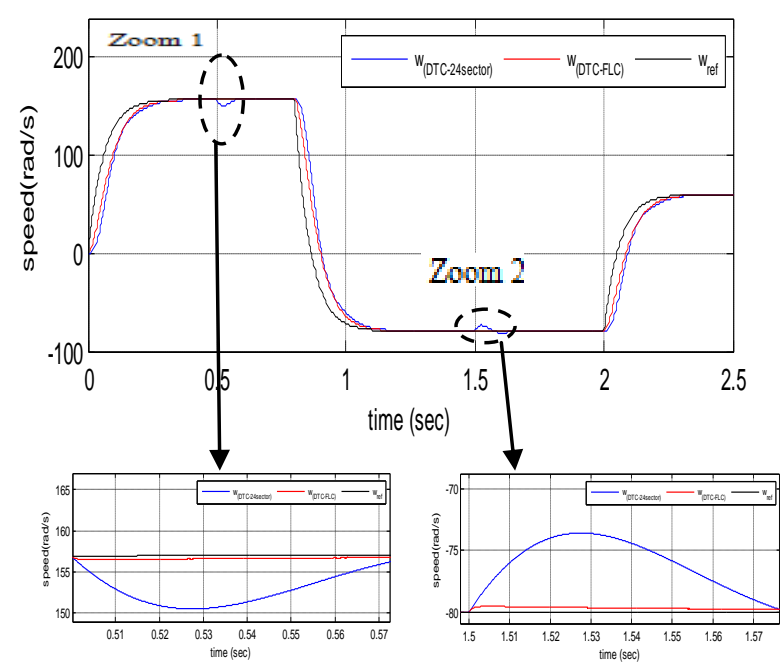

Fig. 16 Speed. 


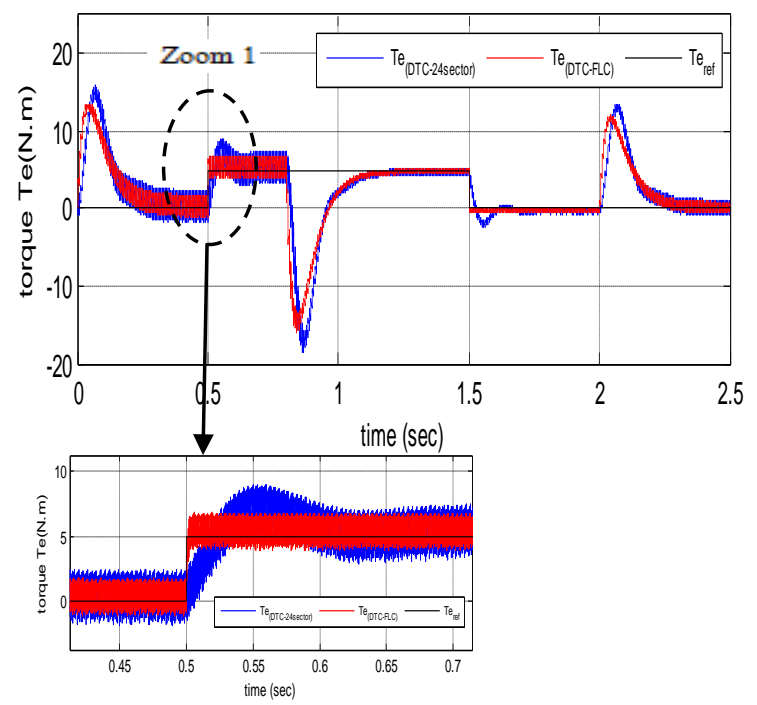

Fig. 17 Torque.
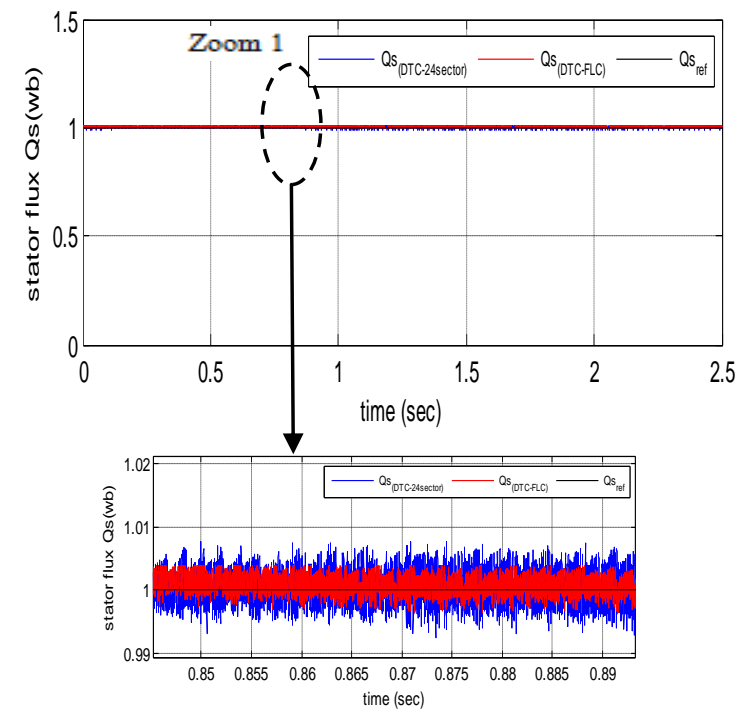

Fig.18 Stator flux.

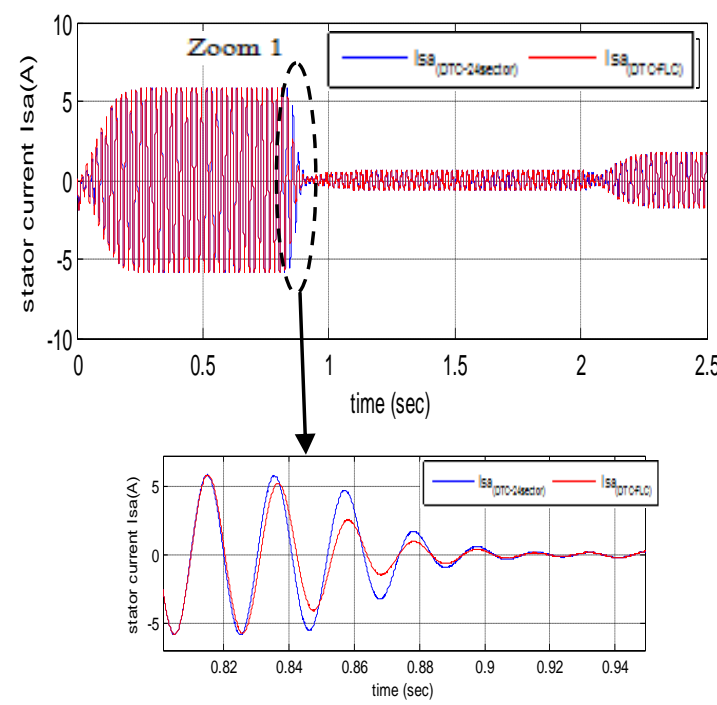

Fig. 19 Stator current.

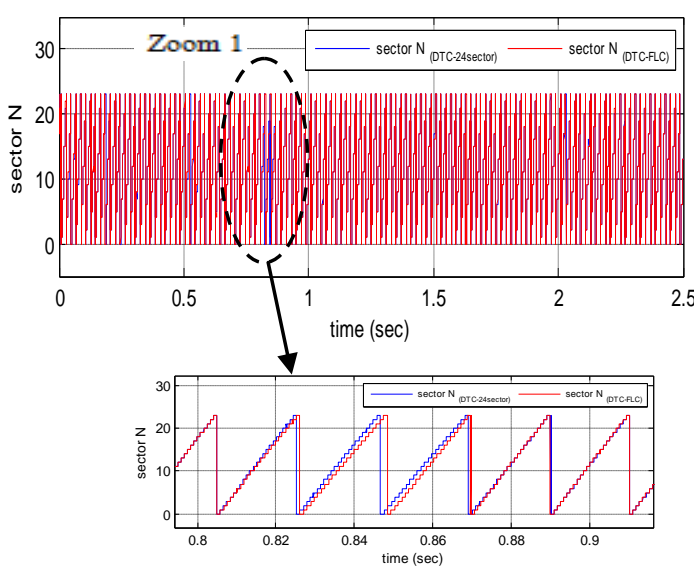

Fig. 20 Sector.

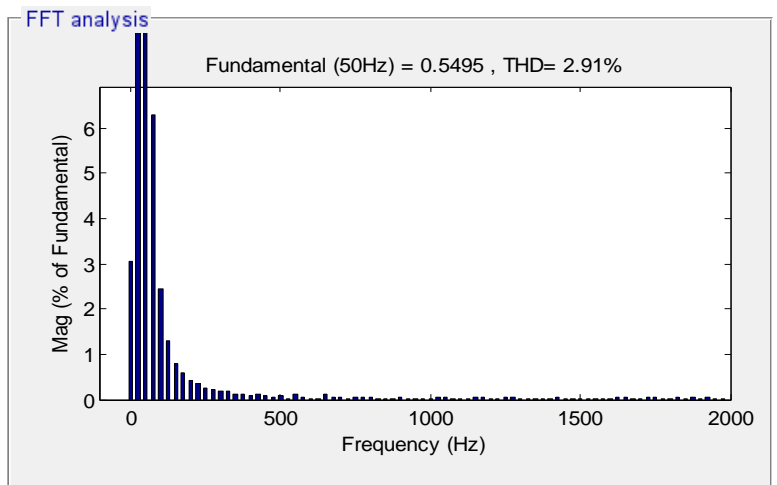

(a)

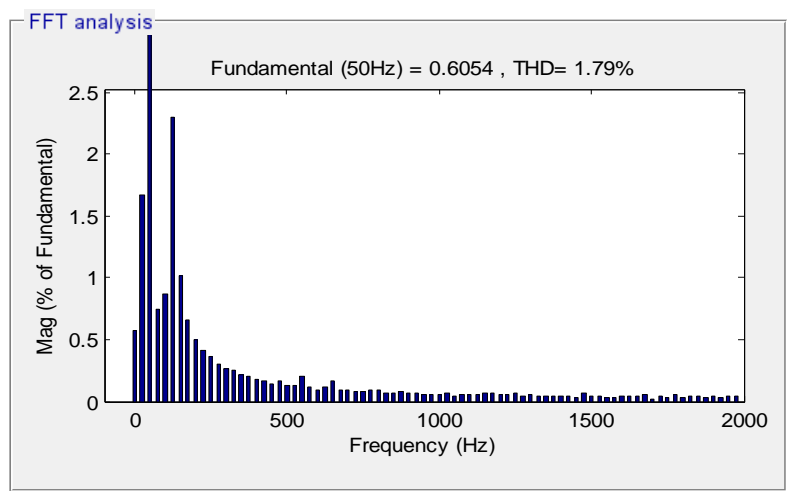

(b)

Fig. 21 THD values:

(a) 24 sectors DTC strategy, (b) 24 sectors fuzzy DTC strategy.

(b)

The results obtained in this test are summarized in Table 4. Through this table, we find that the proposed 24 sectors fuzzy DTC method provided better results in terms of response time compared to the traditional 24 sectors DTC method. 
Table 4. Comparison between the proposed 24 sectors DTC techniques

\begin{tabular}{|c|c|c|}
\cline { 2 - 3 } \multicolumn{1}{c|}{} & $\begin{array}{c}\text { 24 sectors } \\
\text { DTC strategy }\end{array}$ & $\begin{array}{c}\text { 24 sectors } \\
\text { fuzzy DTC } \\
\text { strategy }\end{array}$ \\
\hline $\begin{array}{c}\text { Rise Time of } \\
\text { speed }\end{array}$ & $4.0638 \mathrm{e}+003$ & $3.9651 \mathrm{e}+003$ \\
\hline $\begin{array}{c}\text { Overshoot of } \\
\text { speed }\end{array}$ & 164.0748 & 161.8104 \\
\hline Peak of speed & 158.3021 & 156.9842 \\
\hline $\begin{array}{c}\text { Peak Time of } \\
\text { speed }\end{array}$ & 60469 & 79995 \\
\hline $\begin{array}{c}\text { THD value } \\
(\%) \text { of Isa(A) }\end{array}$ & 2.91 & 1.79 \\
\hline
\end{tabular}

\subsection{Third test}

In this test, the machine parameters are changed and the response of torque, speed, stator current, and stator flux is considered. The effectiveness of the proposed method is also verified in the case of changing the machine parameters compared to the classical method. In this test, the resistance value Rs is changed to $1.5^{*} \mathrm{Rs}$ and with change, the value of Te from 5 N.m to -5 N.m and this is in the time $\mathrm{t}=\left[\begin{array}{ll}0.5 & 1.5\end{array}\right]$.

The results related to this test are shown in the Figs 22 to 27 . Through these figures, we note that torque, stator flux, and speed closely follow the references (see Figs 22 to 24). In addition, we note that the flux is not affected by the change of the torque reference, but rather is independent of it. Fig. 25 shows the stator current of the DFIM fed by the three-level NPC inverter. From this figure, the stator current has a sinusoidal shape. The sector of the designed 24 sectors fuzzy DTC strategy and traditional 24 sectors DTC technique is shown in Fig. 26. The value of regions for both methods is an incremental value from 0 up to 24 on a ladder and then returns to 0 immediately after 24 .

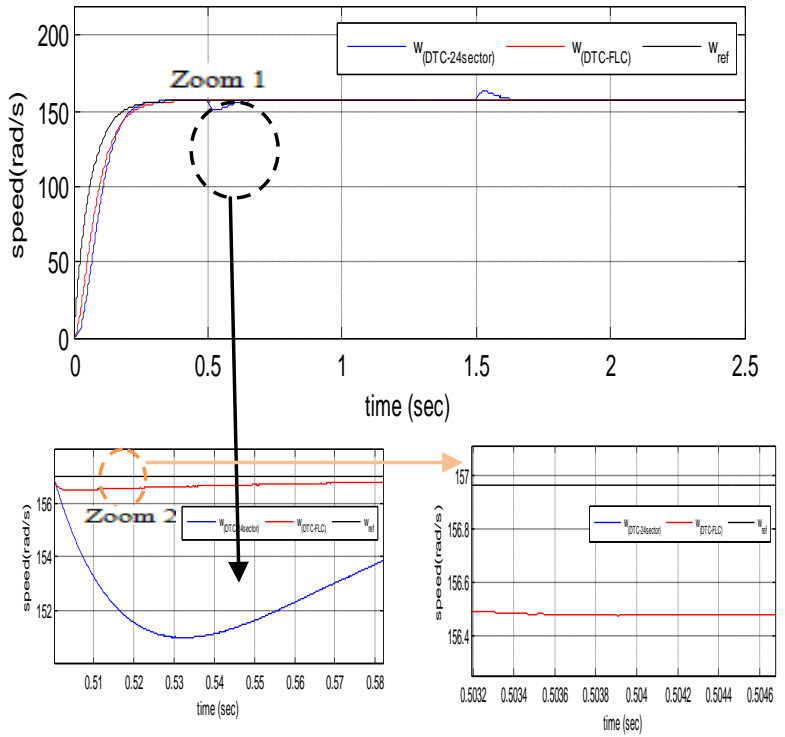

Fig. 22 Speed.

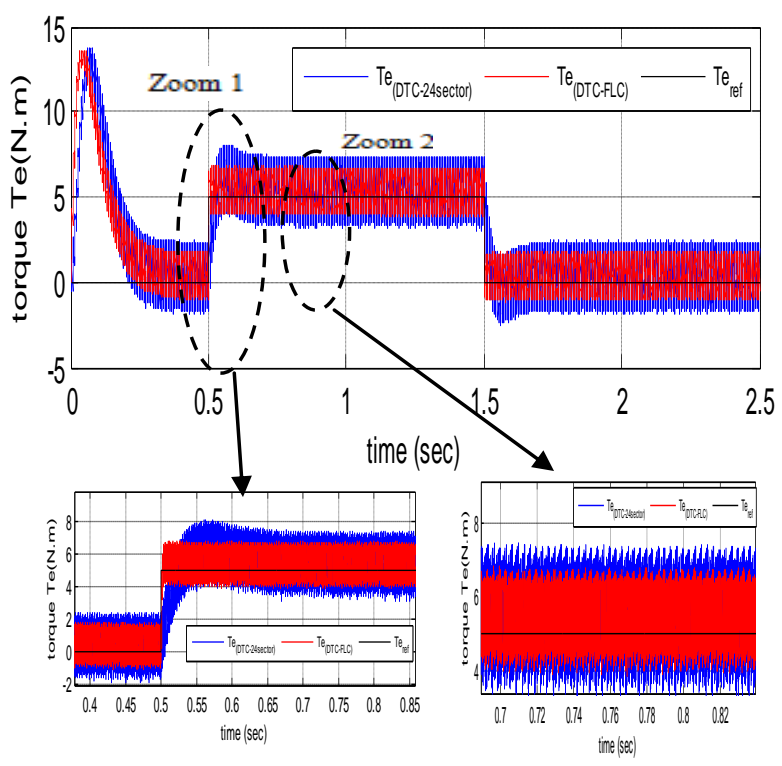

Fig. 23 Torque.

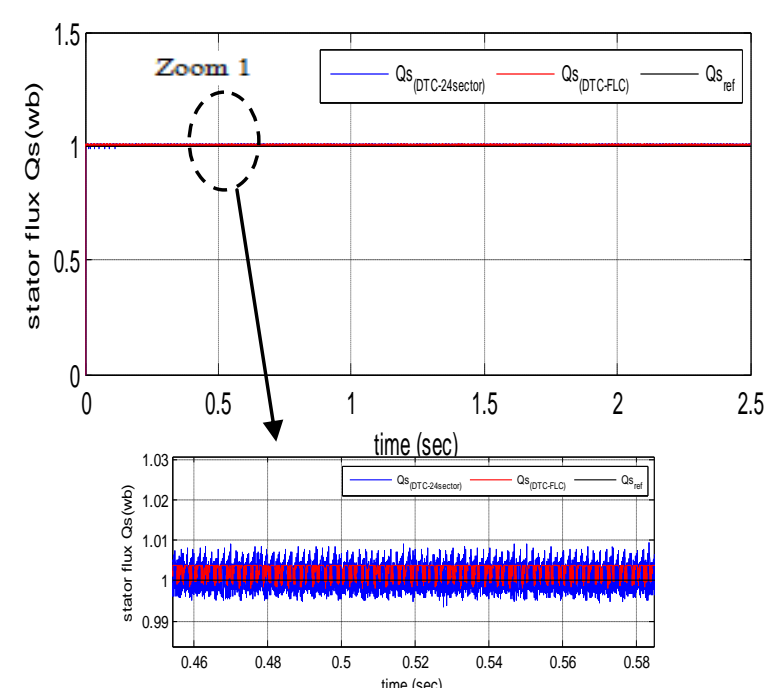

Fig. 24 Stator current. 


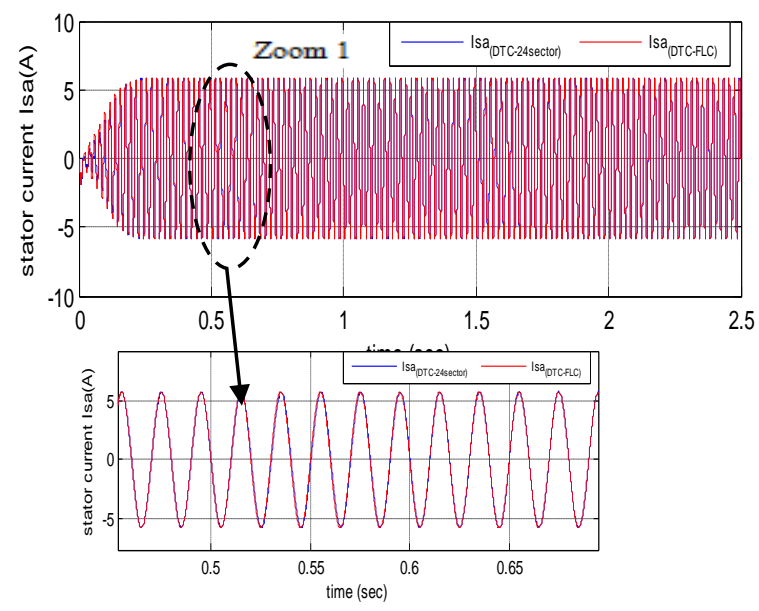

Fig. 25 Stator current.

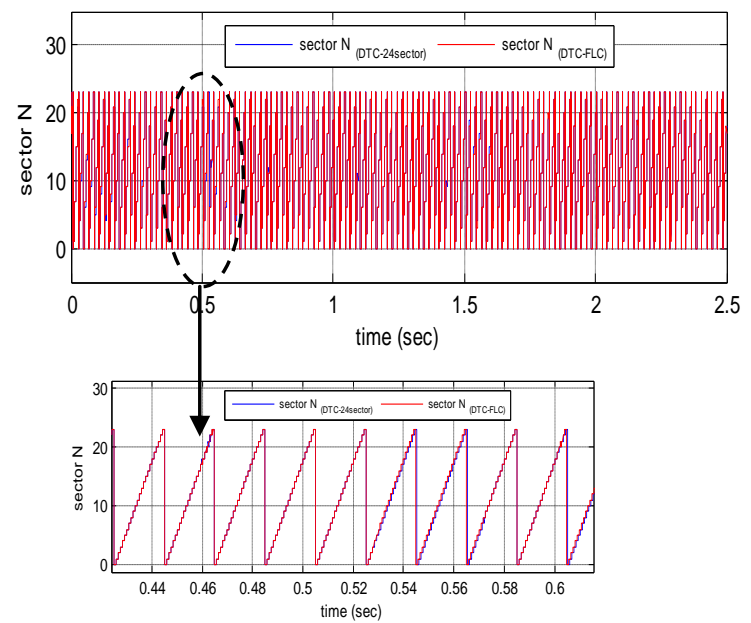

Fig. 26 Sector.

The zoom in the speed, torque, flux, and current is shown in Figs. 22-25, respectively. It can be seen that the proposed 24 sectors fuzzy DTC strategy minimized the undulations in current, torque, and flux compared to the classical 24 sectors DTC strategy.

Fig. 27 shows the THD value of the current of both 24 sectors' DTC strategies. It can be seen through this figure that the THD value is reduced for the proposed 24 sectors fuzzy DTC strategy $(0.40 \%)$ when compared to the classical 24sectors DTC strategy $(1.70 \%)$. The difference between the two 24 sectors DTC techniques appears in the THD value of the stator current, as noted that the proposed 24 sectors fuzzy DTC strategy improve the THD value of stator current about $76.47 \%$ compared to the traditional 24 sectors DTC.

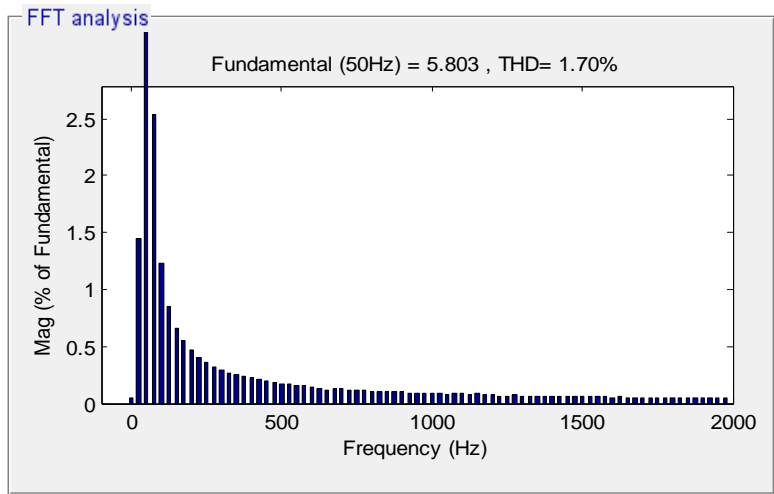

(a)

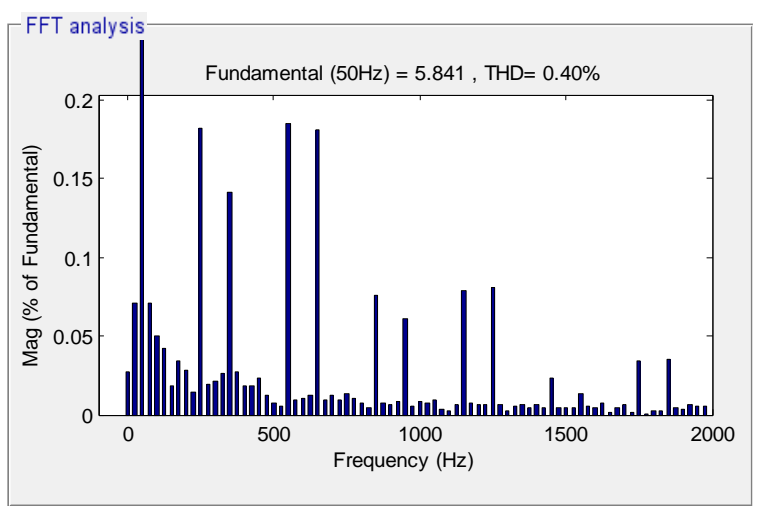

(b)

Fig. 27 THD value of stator current:

(a) 24 sectors DTC strategy, (b) 24 sectors fuzzy DTC strategy.

The results obtained in this test are summarized in Table 5. Through this table, we find that the proposed 24 sectors fuzzy DTC method provided better results in terms of response time compared to the traditional 24 sectors DTC method.

Table 5. Comparison between the both DTC techniques

\begin{tabular}{|c|c|c|}
\hline & $\begin{array}{c}24 \text { sectors DTC } \\
\text { strategy }\end{array}$ & $\begin{array}{c}24 \text { sectors } \\
\text { fuzzy DTC } \\
\text { strategy }\end{array}$ \\
\hline $\begin{array}{l}\text { Rise Time of } \\
\text { speed }\end{array}$ & $1.5350 \mathrm{e}+004$ & $1.3980 \mathrm{e}+004$ \\
\hline $\begin{array}{c}\text { Overshoot of } \\
\text { speed }\end{array}$ & 3.8186 & 0.3054 \\
\hline Peak of speed & 163.0076 & 157.4871 \\
\hline $\begin{array}{l}\text { Peak Time of } \\
\text { speed }\end{array}$ & 153123 & 150498 \\
\hline $\begin{array}{l}\text { THD value (\%) } \\
\text { of Isa }\end{array}$ & 1.70 & 0.40 \\
\hline
\end{tabular}




\section{Conclusion}

In this work, two 24 sectors DTC strategies are designed for controlling the DFIM fed by a threelevel NPC inverter. The strengths of each proposed 24 sectors DTC strategies compared to the rest are mentioned. Also, the new intelligent 24 sectors DTC strategy was embodied using the MATLAB/Simulink software. The proposed intelligent 24 sectors DTC strategy was compared in terms of the value of current, torque, and flux ripples, trace references and the extent of influence in the case of changing the machine parameters.

Through numerical simulation results, we have shown the efficiency of the adopted strategy (intelligent 24 sectors DTC strategy) especially in the attenuation of the ripples at the current, stator flux, and torque levels due to the elimination of the traditional hysteresis comparators. On the other hand, the proposed intelligent 24 sectors DTC strategy reduced the THD value of stator current of the DFIM fed by the three-level NPC inverter compared to the traditional 24 sectors DTC strategy.

The proposed intelligent 24 sectors DTC strategy provides an improvement over the traditional 24 sectors DTC strategy. This improvement is remarkable especially in the torque ripple, quality of current, rotor flux ripple, value of THD and the responses dynamic of speed, torque and rotor flux. The THD minimization can be estimated at $76.47 \%$ in the third test compared to the traditional 24 sectors DTC strategy.

Summarizing, the main findings of this research are as follows:

- A new intelligent hysteresis comparator was presented and confirmed with numerical simulation.

- A new 24 sectors DTC strategy based on fuzzy hysteresis comparators was presented and compared with the traditional 24 sectors DTC strategy.

- Reduce the THD value of current.

- Minimizes the flux, torque, and current ripples.

\section{Appendix}

\begin{tabular}{|l|l|l|}
\hline Variable & Symbol & Value (unit) \\
\hline Power & $\mathrm{Pn}$ & $1.5 \mathrm{kw}$ \\
\hline Frequency & $\mathrm{f}$ & $50 \mathrm{~Hz}$ \\
\hline Pair pole number & $\mathrm{p}$ & 2 \\
\hline Stator resistance & $\mathrm{Rs}$ & $1.75 \Omega$ \\
\hline Rotor resistance & $\mathrm{Rr}$ & $1.68 \Omega$ \\
\hline Mutual inductance & $\mathrm{M}$ & $0.165 \mathrm{H}$ \\
\hline Stator self-inductance & $\mathrm{Ls}$ & $0.295 \mathrm{H}$ \\
\hline Rotor self-inductance & $\mathrm{Lr}$ & $0.104 \mathrm{H}$ \\
\hline Total inertia & $\mathrm{J}$ & $0.01 \mathrm{Kg} \cdot \mathrm{m}^{2}$ \\
\hline
\end{tabular}

\section{References}

[1] O. A. Mohammed, Z. Liu and S. Liu, "A novel sensorless control strategy of doubly fed induction motor and its examination with the physical modeling of machines," in IEEE Transactions on Magnetics, Vol. 41, No. 5, pp. 1852-1855, May 2005, doi: 10.1109/TMAG.2005.846500.

[2] P. Han, M. Cheng and Z. Chen, "DualElectrical-Port Control of Cascaded Doubly-Fed Induction Machine for EV/HEV Applications," in IEEE Transactions on Industry Applications, Vol. 53, No. 2, pp. 1390-1398, March-April 2017, doi: 10.1109/TIA.2016.2625770.

[3] P. Naganathan and S. Srinivas, "VoltageInjected PWM Variants for a Dual TwoLevel Inverter-Fed Open-End Winding Induction Motor Drive," in IEEE Journal of Emerging and Selected Topics in Power Electronics, Vol. 9, No. 2, pp. 1532-1540, April 2021, doi: 10.1109/JESTPE.2020.2972279.

[4] N. K. Bajjuri and A. K. Jain, "Mathematical Modeling and Current-Oriented Control of Double-Inverter-Fed Wound Rotor IM Emulated as Two Virtual Cage Rotor IMs," in IEEE Transactions on Industrial Electronics, Vol. 68, No. 11, pp. 1048810497, Nov. 2021, doi: 10.1109/TIE.2020.3032869.

[5] M. Bodson, "Speed Control for Doubly Fed Induction Motors With and Without Current Feedback," in IEEE Transactions on Control Systems Technology, Vol. 28, No. 3, pp. 898-907, May 2020, doi: 10.1109/TCST.2019.2898372.

[6] H. Benbouhenni, N. Bizon, "Third-Order Sliding Mode Applied to the Direct FieldOriented Control of the Asynchronous Generator for Variable-Speed Contra- 
Rotating Wind Turbine Generation Systems," Energies, Vol. 14, No.18, 1-17, 2021. https://doi.org/10.3390/en14185877.

[7] P. K. Gayen, "Stator Flux Producing Current-Based Promoted Rotor Angle Estimator of Doubly-Fed Induction Generator for Encoder less Operations," in IEEE Sensors Journal, Vol. 21, No. 13, pp. 15133-15141, 1 July1, 2021, doi: 10.1109/JSEN.2021.3072396.

[8] H. Benbouhenni, N. Bizon, "A Synergetic Sliding Mode Controller Applied to Direct Field-Oriented Control of Induction Generator-Based Variable Speed DualRotor Wind Turbines," Energies, Vol. 14, No. 15, pp.1-17, 2021. https://doi.org/10.3390/en14154437.

[9] X. Wang, Z. Wang, M. Cheng and Y. Hu, "Remedial Strategies of T-NPC ThreeLevel Asymmetric Six-Phase PMSM Drives Based on SVM-DTC," in IEEE Transactions on Industrial Electronics, Vol. 64, No. 9, pp. 6841-6853, Sept. 2017, doi: 10.1109/TIE.2017.2682796.

[10] F. Bonnet Francois, P. Vidal and M. Pietrzak-David, "Dual Direct Torque Control of Doubly Fed Induction Machine," in IEEE Transactions on Industrial Electronics, vol. 54, no. 5, pp. 2482-2490, Oct. 2007, doi: 10.1109/TIE.2007.900330.

[11] H. Dan, P. Zeng, W. Xiong, M. Wen, M. $\mathrm{Su}$ and M. Rivera, "Model predictive control-based direct torque control for matrix converter-fed induction motor with reduced torque ripple," in CES Transactions on Electrical Machines and Systems, Vol. 5, No. 2, pp. 90-99, June 2021, doi: 10.30941/CESTEMS.2021.00012.

[12] Z. Zhang, Y. Zhao, W. Qiao and L. Qu, "A Discrete-Time Direct Torque Control for Direct-Drive PMSG-Based Wind Energy Conversion Systems," in IEEE Transactions on Industry Applications, Vol. 51, No. 4, pp. 3504-3514, July-Aug. 2015, doi: 10.1109/TIA.2015.2413760.

[13] H. Benbouhenni, "Utilization of an ANFIS-STSM algorithm to minimize total harmonic distortion," International Journal of Smart Grid, Vol. 4, No. 2, pp. 56-67, 2020.

[14] H. Benbouhenni, "Torque ripple reduction of DTC DFIG drive using neural PI regulators," Majlesi Journal of Energy Management, Vol. 8, No. 2, pp. 21-26, 2019.
[15] M. Abdellatif, M. Debbou, I. SlamaBelkhodja and M. Pietrzak-David, "Simple Low-Speed Sensorless Dual DTC for Double Fed Induction Machine Drive," in IEEE Transactions on Industrial Electronics, Vol. 61, No. 8, pp. 3915-3922, Aug. 2014, doi: 10.1109/TIE.2013.2288190.

[16] F. Mehedi, Adil Yahdou, Abdelkadir belhadj Djilali, Habib Benbouhenni, “ Direct torque fuzzy controlled drive for multi-phase IPMSM based on SVM technique, “ Journal Européen des Systémes Automatisées, Vol. 53, No. 2, pp. 259-266, 2020.

[17] H. Benbouhenni, "Stator current and rotor flux ripples reduction of DTC DFIG drive using FSTSMC algorithm," International Journal of Smart Grid, Vol. 3, No. 4, 2019.

[18] F. Mehedi, H. Benbouhenni, L. Nezli, D. Boudana, "Feedforward neural networkDTC of multi-phase permanent magnet synchronous motor using five-phase neural space vector pulse width modulation strategy," Journal Européen des Systèmes Automatisés, Vol. 54, No. 2, pp. 345-354, 2021. https://doi.org/10.18280/jesa.540217.

[19] A. Berzoy, J. Rengifo and O. Mohammed, "Fuzzy Predictive DTC of Induction Machines With Reduced Torque Ripple and High-Performance Operation," in IEEE Transactions on Power Electronics, Vol. 33, No. 3, pp. 2580-2587, March 2018, doi: 10.1109/TPEL.2017.2690405.

[20] H. Benbouhenni, "Seven-level direct torque control of induction motor based on artificial neural networks with regulation speed using fuzzy PI controller," Iranian Journal of Electrical and Electronic Engineering, Vol. 14, No.1, pp. 85-94, 2018.

[21] H. Benbouhenni, N. Bizon, "Improved Rotor Flux and Torque Control Based on the Third-Order Sliding Mode Scheme Applied to the Asynchronous Generator for the Single-Rotor Wind Turbine," Mathematics, Vol. 9, No.18, 2297. https://doi.org/10.3390/math9182297.

[22] Z. Boudjema, R. Taleb, A. Yahdou, H. Kahal, "High order sliding mode control of a DFIM supplied by two power inverters," Carpathian Journal of Electronic and Computer Engineering, Vol. 8, No. 1, pp. 23-30, 2015. 
[23] H. -S. Kim, Y. -C. Kwon, S. -J. Chee and S. -K. Sul, "Analysis and Compensation of Inverter Nonlinearity for Three-Level TType Inverters," in IEEE Transactions on Power Electronics, Vol. 32, No. 6, pp. 4970-4980, June 2017, doi: 10.1109/TPEL.2016.2607226.

[24] S. Mukherjee, S. K. Giri and S. Banerjee, "A Flexible Discontinuous Modulation Scheme With Hybrid Capacitor Voltage Balancing Strategy for Three-Level NPC Traction Inverter," in IEEE Transactions on Industrial Electronics, Vol. 66, No. 5, pp. 3333-3343, May 2019, doi: 10.1109/TIE.2018.2851967.

[25] H. Benbouhenni, "Amelioration effectiveness of torque and rotor flux control applied to the asynchronous generator $(\mathrm{AG})$ for dual-rotor wind turbine using neural third-order sliding mode approaches," International Journal of Engineering, Transactions C: Aspects, Vol. 35, No. 03, 2022.

[26] I. M. Alsofyani and N. R. N. Idris, "Simple Flux Regulation for Improving State Estimation at Very Low and Zero Speed of a Speed Sensorless Direct Torque Control of an Induction Motor," in IEEE Transactions on Power Electronics, Vol. 31, No. 4, pp. 3027-3035, April 2016, doi: 10.1109/TPEL.2015.2447731.

[27] A. U. Rehman, H. H. Choi and J. -W. Jung, "An Optimal Direct Torque Control Strategy for Surface-Mounted Permanent Magnet Synchronous Motor Drives," in IEEE Transactions on Industrial Informatics, Vol. 17, No. 11, pp. 73907400, Nov. 2021, doi: 10.1109/TII.2021.3053107.

[28] G. Abad, M. Á. Rodriguez and J. Poza, "Two-Level VSC Based Predictive Direct Torque Control of the Doubly Fed Induction Machine With Reduced Torque and Flux Ripples at Low Constant Switching Frequency," in IEEE Transactions on Power Electronics, Vol. 23, No. 3, pp. 1050-1061, May 2008, doi: 10.1109/TPEL.2008.921160.

[29] V. Naik N, S. P. Singh and A. K. Panda, "An Interval Type-2 Fuzzy-Based DTC of IMD Using Hybrid Duty Ratio Control," in IEEE Transactions on Power Electronics, Vol. 35, No. 8, pp. 8443-8451, Aug. 2020, doi: 10.1109/TPEL.2020.2965722.
[30] H. Benbouhenni, N. Bizon, "Advanced Direct Vector Control Method for Optimizing the Operation of a DoublePowered Induction Generator-Based DualRotor Wind Turbine System," Mathematics, Vol. 9, No.19, 2021, 2297. doi: $10.3390 /$ math 9182297.

[31] L. Wang, "A New Look at Type-2 Fuzzy Sets and Type-2 Fuzzy Logic Systems," in IEEE Transactions on Fuzzy Systems, Vol. 25, No. 3, pp. 693-706, June 2017, doi: 10.1109/TFUZZ.2016.2543746.

[32] H. Benbouhenni, "A Novel Direct Active and Reactive Power Control Method Using Fuzzy Super Twisting Algorithms and Modified Space Vector Modulation Technique for an Asynchronous Generatorbased Dual-rotor Wind Powers," Iranian (Iranica) Journal of Energy and Environment, Vol.12, No.2, pp. 109-117, 2021. 